\title{
How many Maximizes in the Balkan Sprachbund
}

\author{
Jessica Rett \\ Rutgers University
}

\section{Introduction}

This paper begins by arguing that the words many and much (and their Balkan counterparts) are modifiers of degrees, type $\langle\langle d, t\rangle,\langle d, t\rangle\rangle$. They denote functions from a set of $d$-degrees (the scale $D$ ) to a singleton set of the degree $d^{\prime}$, which is the measure of $D$. This analysis is based on arguments made by Wheeler (1972), McConnell-Ginet (1973) and Klein (1982) and goes against those put forth by e.g. Keenan (1996) and Hackl (2000). It then demonstrates that such an analysis allows for a compositional account of the semantic differences between Balkan degree questions that are monomorphemic and their counterparts with an additional overt many. These examples are from Romanian:
a. Cîte femei cunoaşte?
citt-Fpl women know-3sg
b. Cît de multe femei cunoaşte?
cît of many-Fpl women know-3sg
'How many women does he know?'

The question in (1a) uses the Romanian degree $w h$-word, citt, to ask about the number of women John knows. This construction displays the same properties as English quantity questions: its individual quantifier exhibits scope ambiguities when the question contains a modal, and it is compatible with upward-scalar predicates in addition to downward-scalar predicates.

The question in (1b) contains an overt mult ('many') in addition to the degree $w h$-word cit. Mult questions differ from their monomorphemic counterparts in their inability to occur with upward-scalar questions. I show that this difference can be accounted for by incorporating a compositional analysis of mult as a measure of sets, an analysis that does not require postulation of a maximality operator, contra Rullman (1995).

While a monomorphemic quantity question involves quantification over degrees $d$ that are quantities of sets of individuals, mult questions involve quantification over the degree $d^{\prime}$ that is the size of the scale $D$ containing the quantities

Thanks to Roger Schwarzschild for his help and patience. I'm indebted to Adrian Brasoveanu for bringing these data to my attention, and to him as well as Mark Baker, Ileana Comorovski, Sam Cumming, Veneeta Dayal, Viviane Déprez, Danny Fox, Irene Heim, Nathan Klinedinst, Angelika Kratzer and Maribel Romero for discussing the paper with me. Adrian Brasoveanu, Oana Ciucivara and Ileana Comorovski provided the Romanian judgments; thanks also to Slavica Kochovksa and Igor Kochovski for their help with Macedonian, and Ljuba Veselinova and a SALT reviewer for their Bulgarian judgments. 
$d$ of sets of individuals. When the question predicate is downward-scalar (that is, when an inference from $d$ to $d-1$ holds), the size of the scale $D$ is the same as the maximum degree $d$ in $D$. When the question predicate is upward-scalar (when an inference from $d$ to $d+1$ holds), the size of the set of quantities is not informative, and a mult question is infelicitous.

In addition to supporting the characterization of mult as a degree modifier, this analysis demonstrates against the notion that a maximality operator is built into the meaning of quantity questions (Rullman 1995). It instead supports the idea that maximality in questions is achieved pragmatically (when necessary), following Dayal (1996) and Beck and Rullman (1999).

I'll refer to the words many, much, mult in Romanian and mnogu in Macedonian as ' $m$-words'. These words are all minimally characterized by their ability to modify scales of quantity. However, much as well as mnogu in Macedonian, can additionally modify scales of gradability.

a. The senate just approved a much needed budget reform.

b. Taa e mnogu visoka.

she is much tall

'She is pretty tall.'

Many and much in English additionally differ in the types of quantity scales they modify. Many modifies quantity scales associated with count nouns (non-dense quantity scales), while much modifies quantity scales associated with mass nouns (dense quantity scales), although there are some exceptions to this (e.g. furniture).

a. James didn't order many pizzas.

b. Adam reads many more books than Nathan.

a. Danny didn't drink much beer.

b. Karen eats much more cheese than Sam.

\section{The Meaning of $M$-words}

In this section, I argue that $m$-words like many and much are not generalized quantifiers nor comparative determiners but are modifiers of sets of degrees (which I refer to as 'scales') of type $\langle\langle d, t\rangle,\langle d, t\rangle\rangle$.

\subsection{M-words are Degree Modifiers}

Wheeler (1972), McConnell-Ginet (1973) and Klein (1982: 132) argue from the behavior of much in differential comparatives like (5) that it's a modifier of scales: "This just means that the set denoted by $(5 b)$ - let us call it ' $G$ ' - will be relatively large. ... [I]t seems as though $\mathrm{G}$ represents the 'distance' between Chris and Alex with respect to the predicate tall. This makes it highly plausible that much should be interpreted as a measure on the set of G." 

a. Chris is much taller than Alex.
b. $\operatorname{much}(\lambda d[(d($ tall $))($ Chris $) \wedge \neg(d($ tall $))($ Alex $)])$

On a first pass, this gives us the $m$-word meaning in (6), where $\mu$ is a measure of sets. In (6) much is a function from the set of degrees $D$ to the singleton set containing $d^{\prime}$, which is the size of the set of $D .^{1}$

$$
\lambda D_{\langle d, t\rangle} \lambda d^{\prime} . \mu(D)=d^{\prime}
$$

Similar analyses of $m$-words, referred to elsewhere as measure phrases or QPs, surface in Zwart (1997) and Schwarzschild (2006). There are competing theories of the meaning of $m$-words; I'll describe a recent one which characterizes $m$-words as determiners and then show why the analysis here does not share in its shortcomings.

\subsection{Comparative Determiners}

Hackl (2000: 150) follows other analyses (Heycock 1995, Romero 1998, Fox 2000, Lahiri 2002) in characterizing $m$-words as determiners that associate a degree $d$ with the size of the set of individuals denoted by the NP they occur with.

$$
\llbracket \text { many } \rrbracket=\lambda d \lambda P \lambda Q \exists X . X \text { has } d \text {-many elements \& } P(X) \& Q(X)
$$

There are two main motivations for doing this. The first comes from reconstruction effects in quantity questions; the fact that (8a) has the two different interpretations in (8b) and (8c) indicates that its degree quantification and individual quantification are introduced by two separate operators.

a. How many books did John have to read?

b. For what \# $\mathrm{n}$ : there are $\mathrm{n}$ books $\mathrm{x}$ st. $\mathrm{J}$ has to read $\mathrm{x}$.

c. For what \# n: it has to be the case that there are $\mathrm{n}$ books $\mathrm{x}$ st. J reads $\mathrm{x}$.

The first reading ( $8 \mathrm{~b})$ is available in a situation in which John is taking a semantics class and there are three books (books A, B, and C) such that John has to read them to pass the class. The second reading $(8 \mathrm{c})$ is available in a situation in which John is taking a speed-reading course: it's not the case that there are any books such that he has to read them, but in order to pass the class, he has to read 100 books.

These analyses attribute the individual quantification and the degree argument on the NP in (8b) and (8c) to many. (This meaning of many is the same as when the phrase 'seven pizzas' is translated as 'seven-many pizzas'.) It attributes the degree quantification in $(8 \mathrm{~b})$ and $(8 \mathrm{c})$ to the wh-word how. The meaning in (8b) is attained when the word many raises with the $w h$-word above the modal. The

\footnotetext{
${ }^{1}$ Many and much additionally have an 'evaluative' aspect of meaning in positive constructions, where the measure of degrees is located high on the scale of measures with respect to a contextuallyset cut-off point. It's possible that this aspect of meaning is contributed by a version of the positive operator POS, proposed for gradable adjectives in absolute constructions in e.g. Cresswell (1976) and Kennedy (1999). See Rett (2007) for a detailed analysis which encodes evaluativity in a null degree modifier EVAL.
} 
meaning in $(8 \mathrm{c})$ is attained when the word many is reconstructed in its base position, below the modal.

The second motivation for the meaning of many in (7) comes from additional work by Hackl on the scope possibilities of the comparative, especially from what he calls 'Minimal Number Predicates,' which are instantiated in the contrasting pair in (9):

a. ??More than one student is meeting.

b. No fewer than two students are meeting.

Hackl argues that the best way to account for the data in (9) is to argue that the matrix VP be meeting is interpreted in the than-clause, following the paraphrases in (10).

a. ??More students are meeting than how many students there are in $\underline{\text { a }}$ meeting of one student.

b. No fewer students are meeting than how many students there are in a meeting of two students.

This reduces the ungrammaticality of (9a) to the fact that its interpretation in (10a) contains the unacceptable phrase "meeting of one student". Drawing from arguments in Bresnan (1973) that the NP needs to be interpreted inside the than-clause, too, for sentences like "I've never met a taller man than my mother," Hackl proposes that the than-clause contains a determiner with two predicate arguments. Crucially, he makes no specific arguments that this determiner meaning needs to be tied to many. He assumes this meaning is attached to many because he interprets the phrase 'one student' as having the LF 'one-many student'.

Although it's clear that natural language encodes the meaning in (7) and even uses it in the interpretation of quantity questions (and to select for Minimal Number Predicates in (9)), I argue below that this meaning should not be attributed to many, but rather to a null operator that's more closely associated with the NP.

\subsection{Quantity Operators and M-words}

The first reason to disassociate the meaning in (7) from the word many comes from the simple fact that many languages do not utilize an overt $m$-word in quantity questions. Question words like cît in Romanian, kolko in Bulgarian and kolku in Macedonian can't be obviously separated into a degree quantifier and an $m$-word.
a. Cîte femei cunoaşte?
Romanian
cît-Fpl women know-3sg
b. Kolku ženi poznava (toj)? Macedonian
kolku women know-3sg (he)
'How many women does he know?'


This fact isn't enough to argue that $m$-words don't encode individual quantification; a defender of the view could argue that these constructions do in fact contain a covert $m$-word that has the meaning in (7).

But this cannot be the case. Each of the constructions in (11) can also occur with an optional overt $m$-word:
a. Cît de multe femei cunoaşte?
Romanian
b. Kolku mnogu ženi poznava (toj)?
Macedonian
kolku many women know-3sg (he)
'How many women does he know?'

The fact that these constructions differ syntactically and semantically (in ways that will be explored in Section 3) indicates that the constructions in (11) aren't just the constructions in (12) with a covert $m$-word.

A second argument against associating the meaning in (7) with $m$-words comes from quantity questions in French. French allows the NP associated with the quantity $w h$-phrase to be optionally stranded in its base position.
a. Combien de livres faut-il que vous lisiez?
how.many of books it's.necessary that you read
b. Combien faut-il que vous lisiez de livres? how.many it's.necessary that you read of books 'How many books must you read?'

The construction in (13a) is ambiguous just like its English counterpart is; (13b), however, only allows for the low-scope reading of the individual quantifier (Obenauer 1984, Rizzi 1990, Dobrovie-Sorin 1992, Heycock 1995). Analyses that attribute existential quantification to the morpheme many (Heycock 1995, Romero 1998, Fox 2000, Hackl 2000) face a challenge from the data in (13b): whenever the NP is pronounced low, the individual quantifier scopes low. What aspect of these analyses ensures that the interpretation of the word many be so closely tied to the pronunciation of the NP?

The data in (13b) follow straightforwardly given the assumption that the individual quantifier is instead contributed by a covert morpheme more closely associated with the NP. When the NP is raised with combien, wh-movement allows this morpheme to escape its own clause. Once raised, it can either scope over the modal operator or under it. When the NP is not raised with combien, the morpheme can only move via QR (assuming it moves as a quantified NP with the Quantity Operator), which is clause-bound. This prevents it from being able to scope outside of its own clause, leaving it under the scope of the modal operator. To assume that the individual variable is associated with an $m$-word component of the $w h$-phrase is to lose this explanation for the unambiguity of (13b).

I've demonstrated that the definition in (7) shouldn't be associated with $m$ words, but the meaning is needed nevertheless. Something contributes existential quantification over individuals in quantity questions like those in (8a) and (13), and 
something provides the set of individuals with a degree argument.

Cresswell (1976) argues that plural and mass nouns are two-place predicates of the form ' $x$ is a $y$-membered set of men' (for plural count nouns) and ' $x$ is an amount of NP $y$ ' (for mass nouns). He derives these revised meanings in degree constructions using the two operators 'Pl' and 'Tot', respectively. They take as their arguments the property denoted by the verb and the property denoted by the mass noun, and return a set of amounts. (Tot additionally takes as an argument a contextually-salient measure, like 'volume' or 'weight').

Schwarzschild (2006) argues for a similar morpheme from a syntactic point of view; he argues that measure phrases like many occur in the specifier of a functional projection above NPs, resulting in agreement in some languages (e.g. with molt in Italian). He makes the case that this head additionally constrains the dimensions of the noun in terms of monotonicity, likening its function in this respect to the assigner of a Measure $\theta$-role (Abney 1987). This morpheme is called 'Mon'. Kayne (2005), too, proposes a covert morpheme NUMBER in English based on the semantic similarity between (14a) and (14b), among other things. ${ }^{2}$

a. John has few books.

b. John has a small number of books.

I borrow from these accounts, referring to the operator on count nouns as Count (COUNT) and the operator on mass nouns as Measure (MEASURE). I will refer to them collectively as Quantity Operators. Note that these meanings resemble Hackl's many in (7), and so they retain his account of Minimal Number Predicates, as well as traditional accounts of the ambiguity of quantity questions (changing only the source of responsibility for predicate selection on the one hand and quantifier scope on the other). The two Quantity Operators differ only in their measure.

$$
\begin{aligned}
& \llbracket \mathrm{COUNT} \rrbracket=\lambda P \lambda d \lambda Q \exists X . P(X) \wedge Q(X) \wedge|X|=d \\
& \llbracket \mathrm{MEASURE} \rrbracket=\lambda P \lambda d \lambda Q \exists x . P(x) \wedge Q(x) \wedge \mathscr{M}(x)=d
\end{aligned}
$$

In (15), $X$ is a set variable and $|X|$ is the cardinality of various sets $X$. In (16), $x$ is a portion of matter and $\mathscr{M}(x)$ is a measure of various portions of matter. The measure varies contextually (for volume, weight, etc.). ${ }^{3}$

When its two predicate arguments are filled in, COUNT denotes a set of degrees from one to the maximum number of individuals that satisfy these predicates. Because the nature of this set of quantities plays a role in the analysis in Section 3,

\footnotetext{
${ }^{2}$ The fact that $m$-words can take a determiner at all (this holds for many, as well, in 'The many ants were clustering around the spilled food'), is another potential argument against an analysis of $m$-words as determiners. However, see Hackl (2000): Chapter 3 for an analysis of these apparent stacking determiners as instances of reduced appositive relative clauses.

${ }^{3}$ Both the cardinality operator in (15) and the operator $\mathscr{M}$ in (16) might additionally effect whether a degree construction receives a cardinal or proportional reading that has previously been attributed to different interpretations of the word many (Westerstähl 1985, Partee 1989). Doetjes (1997: Chapter 6) observes that the cardinal and proportional readings occur with number measure phrases as well, a generalization that is compatible with encoding the variation in the Quantity Operators on the nouns rather than the measure words themselves.
} 
I'll demonstrate how this is so. Imagine a scenario in which there are three pizzas on the table: $\mathrm{m}$ (ushroom), $\mathrm{p}$ (roscuitto) and e(ggplant). The set of degrees denoted by COUNT is as in (17):

$$
\begin{array}{ll}
\text { a. } & \lambda d \exists X \cdot \operatorname{pizzas}(X) \wedge \text { on-table }(X) \wedge|X|=d \\
\text { b. } & \{1,2,3\}
\end{array}
$$

The set $\{\mathrm{m}, \mathrm{p}, \mathrm{e}\}$ is in the denotation of pizzas and on the table, and $|\{\mathrm{m}, \mathrm{p}, \mathrm{e}\}|=3$, so the degree 3 is in the set of degrees denoted by COUNT. The set $\{\mathrm{m}, \mathrm{p}\}$ (along with $\{\mathrm{m}, \mathrm{e}\}$ and $\{\mathrm{p}, \mathrm{e}\})$ is also in the denotation of pizzas and on the table and $|\{\mathrm{m}, \mathrm{p}\}|=$ 2 , so 2 is in the set. Finally, $\{\mathrm{p}\}$ (along with $\{\mathrm{e}\}$ and $\{\mathrm{m}\}$ ) is in the denotation of pizza and on the table and $|\{\mathrm{p}\}|=1$, so 1 is in the set. There is no set of a pizzas on the table with the cardinality 4; similarly, the null set is not in the denotation of pizzas and on the table, so the cardinality 0 is not in the set in (17).

The measure of portions of matter introduced in (16) is analogous, but differs in that it involves quantification over portions of matter rather than sets of individuals. When its two predicate arguments are filled in, MEASURE denotes a set of degrees including the e.g. weight of the heaviest portion of matter true of both predicates, and all real numbers between this weight and zero. Take a scenario in which there is a 2-lb. lump of pizza dough on the counter.

$$
\begin{array}{ll}
\text { a. } & \lambda d \exists x \cdot \operatorname{pizza}-\operatorname{dough}(x) \wedge \text { on-table }(X) \wedge \mathscr{M}(x)=d \\
\text { b. } & \{\ldots .1, \ldots .2, \ldots . \ldots 1, \ldots 1.8, \ldots 1.9 \ldots 2\}
\end{array}
$$

There is a 2-lb portion of dough on the counter, so the number 2 is in the set of degrees denoted by MEASURE. There is also a 1.9-lb portion of dough on the counter, so the number 1.9 is in this set of degrees. Similarly, there is a 1.95lb portion, a 1.925 portion, a 1.9125 portion, and so on, for all the real numbers between 0 and 2. The Quantity Operator MEASURE, just like COUNT, denotes a set of degrees (either cardinal or real numbers) between zero and the highest degree that is in the denotation of the NP and the VP.

In sum, Quantity Operators do the work previously associated with $m$-words: they provide existential quantification over individuals while associating the size of the set of individuals with a degree argument. Evidence from French split-NP constructions indicates that this meaning should be attributed to a null morpheme associated with the NP, rather than to the $m$-word. The fact that $m$-words seem to work as degree modifiers, which is the topic of Section 3, also gives reason to associate the meanings in (15) and (16) with something other than $m$-words.

\section{Quantity Questions in Romanian}

This section involves an analysis of the difference between monomorphemic and $\mathrm{m}$ word quantity questions in the Balkan languages. Quantity questions in Romanian can take one of two forms: 

a. Cîte femei cunoaşte?
cît-Fpl women know-3sg
b. Cît de multe femei cunoaşte?
cît of many-Fpl women know-3sg
'How many women does he know?'

I assume that the only difference between the two constructions is that (19b), but not (19a), contains the $m$-word mult, the definition of which is repeated below.

$$
\lambda D_{\langle d, t\rangle} \lambda d^{\prime} . \mu(D)=d^{\prime}
$$

This assumption considers the linker $d e$ to be semantically (but not necessarily syntactically) uncontentful. ${ }^{4}$

\subsection{The Data}

One of the main differences between monomorphemic quantity questions like (19a) and mult quantity questions like (19b) is that the former, but not the latter, are felicitous in upward-scalar (21) contexts (I'll discuss non-scalar contexts in 3.3). ${ }^{5}$

(21) We have few eggs left in the house.

a. Cîte ouă ajung ca să iasă prăjitura bună? cît-Fpl eggs are.enough compl Subj come.out cake good

b. \#Cît de multe ouă ajung ca să iasă prăjitura bună? cît of many-Fpl eggs are.enough compl Subj come.out cake good 'How many eggs are sufficient so that the cake comes out good?'

Characterizations of these contexts as upward- or downward-scalar refer to the matrix verb in a quantity question. Downward-scalar predicates, like be on the table, the example from Section 2.3, allow you to infer from the fact that a given set $\mathrm{X}$ is in the denotation of the VP to the fact that a subset of $\mathrm{X}$ is also in the denotation of the VP. Upward-scalar predicates, on the other hand, allow inference only from the set X to its superset. Take, for instance, the question 'How much money can a graduate student live on?' It's clearly asking for a lower-bound, unlike downwardscalar questions, which ask for upper-bounds. In a scenario in which a graduate student can live on $\$ 20,000$, it's not the case that he can also live on $\$ 15,000$, but it's reliably the case that he can live on $\$ 21,000, \$ 200,000$, and so on.

\footnotetext{
${ }^{4}$ Abeillè et al. (to appear) and Kayne (2005) independently propose that the linker de in French has a denotation something like those in (15) and (16). However, this analysis cannot naturally be extended to Romanian, where the distribution of de seems exactly the opposite of the distribution

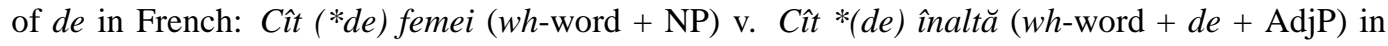
Romanian; Combien *(de) livres (wh-word + de $+\mathrm{NP})$ v. Combien $(* d e)$ souvant (wh-word + AdvP) in French.

${ }^{5}$ The hash mark here represents that the sentence is unacceptable, but that the judgment varies across speakers. Despite this variation, most of my informants agree that (21b) is more awkward than (21a). See Section 3.3 for additional discussion of judgment variation.
} 
Beck and Rullman (1999) use the felicity of quantity questions in upwardscalar contexts to argue that the semantics of these questions can't contain a maximality operator. Given that mult questions are incompatible with upward-scalar questions, it seems like the addition of the $m$-word in quantity questions contributes a maximality effect to the truth conditions of these constructions. I argue that this effect falls out of an account with the correct definition of $m$-words as degree modifiers, and thus does not require the postulation of a covert maximality operator, contra Rullman (1995).

\subsection{The Analysis}

My account of the infelicity of (21) follows straightforwardly from the independently motivated meanings of $m$-words (20) and the Quantity Operators in (15) and (16). I also assume citt is a $[+w h] \mathrm{Deg}^{\circ}$ whose semantics includes quantification over degrees.

$$
\llbracket \mathrm{cît} \rrbracket=\lambda D \lambda p^{\prime} \exists d \cdot D(d)\left(p^{\prime}\right)
$$

This is the same meaning attributed to the degree wh-word how in English: it is no surprise, then, that the same word is used to question the degree of adjectival predicates (23):

$$
\begin{aligned}
& \text { Cît de înaltǎ este? } \\
& \text { cît of tall-Fsg is.she? } \\
& \text { How tall is she? }
\end{aligned}
$$

\subsubsection{The Semantics of Monomorphemic Quantity Questions}

The right truth conditions of monomorphemic quantity questions come from a compositional account involving meaning of the Quantity Operator COUNT (15) and $c \hat{t} t$ as it's defined in (22). I'll discuss questions with mass nouns in Section 3.2.2.

The derivation of an example monomorphemic question follows below. ${ }^{6}$
a. Cîte femei cunoaşte?
cît women know-3sg
How many women does he know?
b. $\quad\left[{ }_{\mathrm{CP}} c \hat{\imath}_{d_{1}} \mathrm{C}^{\circ}\left[\mathrm{t}_{d_{1}} \text { COUNT women }\right]_{\mathrm{X}}\left[\mathrm{IP}\right.\right.$ he knows $\left.\left.\mathrm{t}_{X}\right]\right]$

\footnotetext{
${ }^{6}$ I use a Karttunen (1977) semantics of questions here, but am not committed to a requirement that the propositions denoted by a question be true. Thanks to Angelika Kratzer for discussion here.
} 


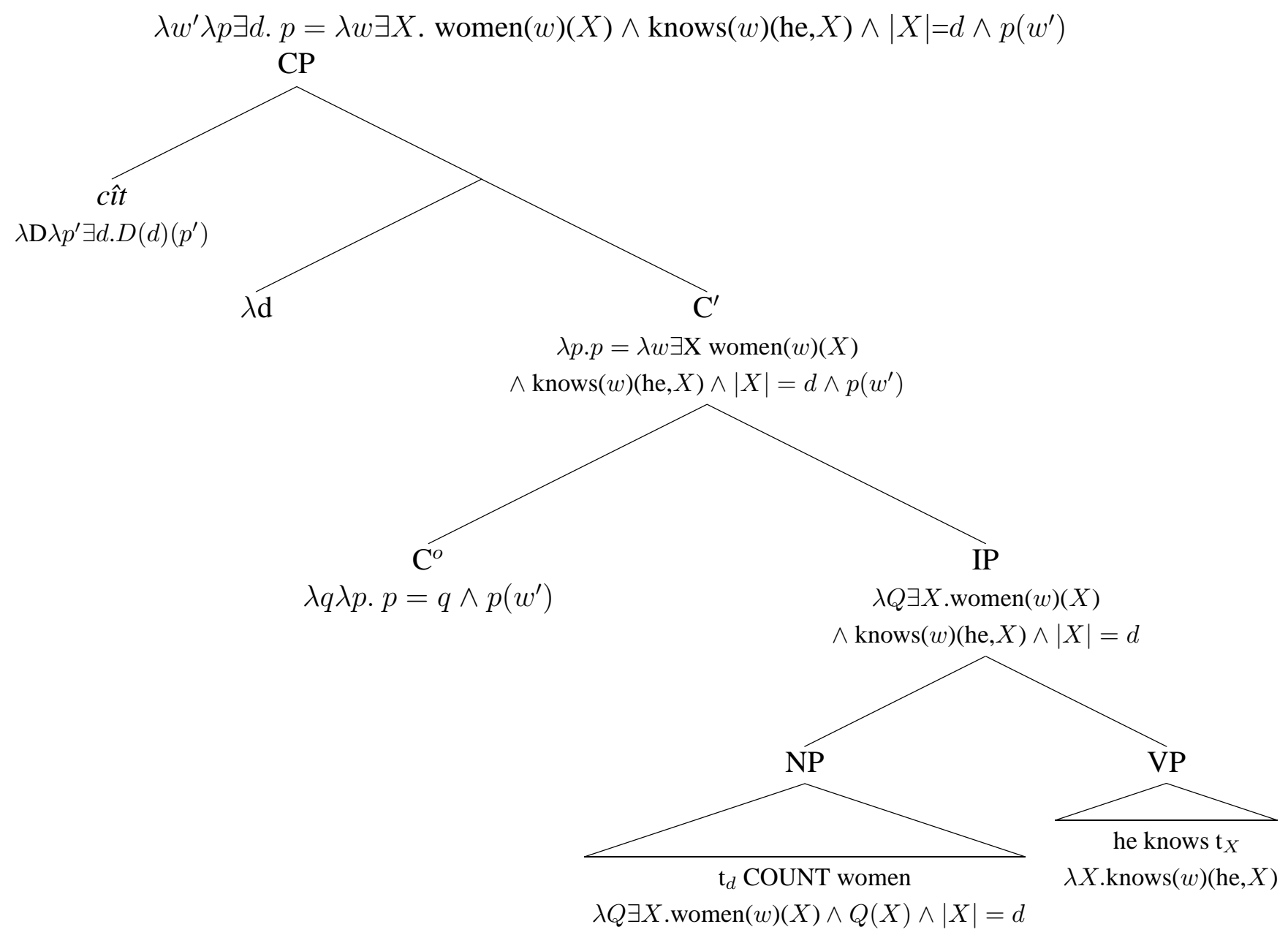

Let's say that John knows 5 women in world $w_{a}$. Then the question in (24) is a function that maps $w_{a}$ onto the set $\{\lambda w$ John knows 1 woman in $w, \lambda w$ John knows 2 women in $w, \lambda w$ John knows 3 women in $w, \lambda w$ John knows 4 women in $w, \lambda w$ John knows 5 women in $w\}$. Following Dayal (1996) and Beck and Rullman (1999), pragmatic restrictions pick out the maximally informative proposition 'John knows 5 women' from this set.

\subsubsection{The Semantics of Mult Questions}

The semantics of cît de mult constructions work differently due to the presence of the $m$-word.

(25) a. Cît de multe femei cunoaşte? cît of many women know.3sg

How many women does he know?

b. $\quad\left[\mathrm{CP} c \hat{\imath} t_{d^{\prime}} \mathrm{C}^{o} \mathrm{t}_{d^{\prime}}[\text { multe }]_{\mathrm{d}}\left[\mathrm{t}_{d} \mathrm{PL} \text { women }\right]_{\mathrm{X}}\right.$ [IP he knows $\left.\left.\mathrm{t}_{X}\right]\right]$ 
$\lambda w^{\prime} \lambda p \exists d^{\prime} \cdot \mathrm{p}=\lambda w \cdot \mu(\lambda d \exists X \cdot \operatorname{wmn}(w)(X) \wedge \operatorname{knws}(w)($ he, $X) \wedge|X|=d)=d^{\prime} \wedge p\left(w^{\prime}\right)$

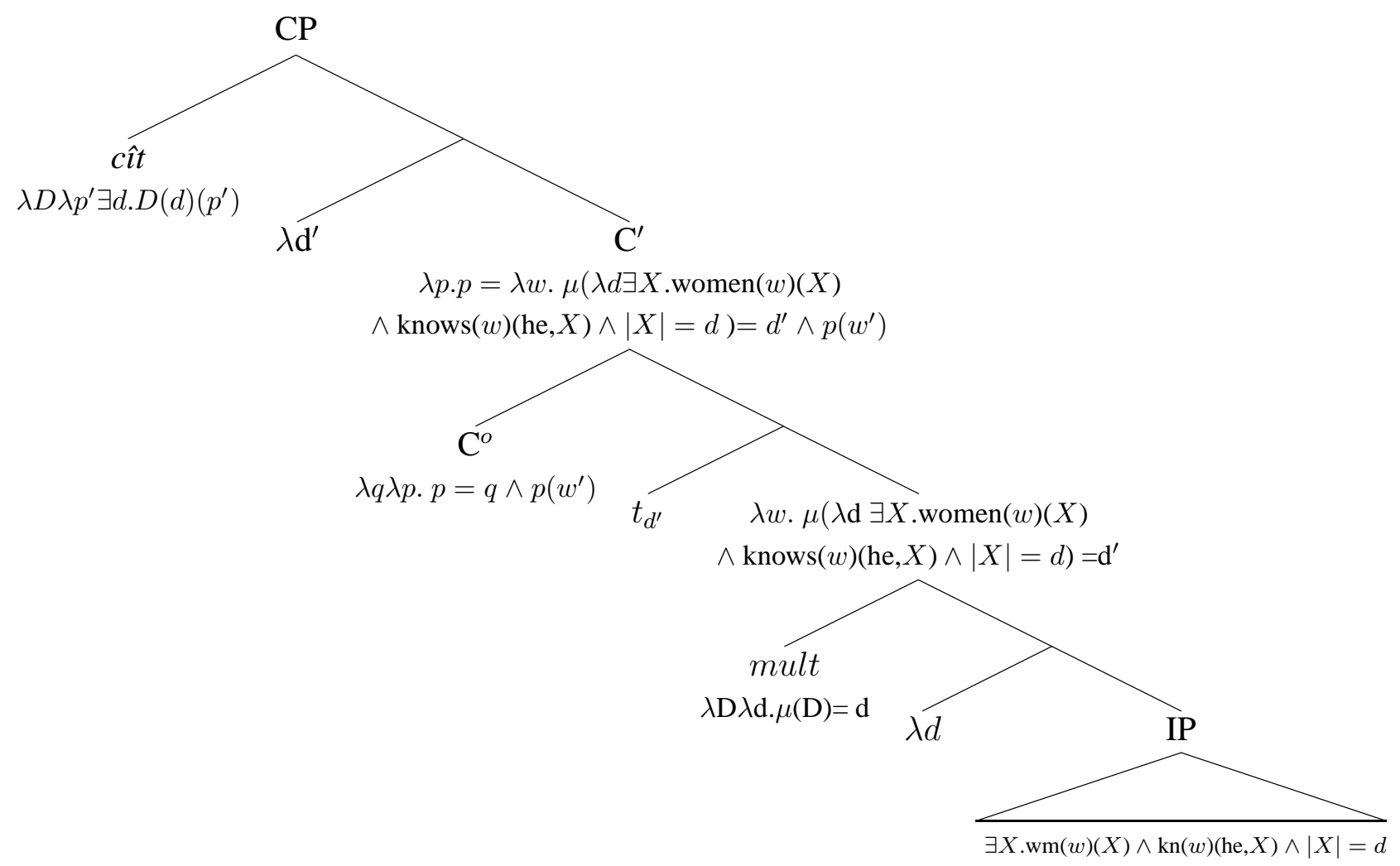

Let's again take a world $w_{a}$ in which John knows 5 women. The numbers $d$ of women he knows compose the set $D=\{1,2,3,4,5\}$. The measure $\mu$ incorporated in the meaning of $m$-words is defined over sets of degrees, and attributes to the scale $D$ a size $d^{\prime}$. In this case, $D$ contains 5 degrees, so $d^{\prime}=5$. It is this degree variable that is existentially bound by the wh-word, and the question in (25) is a function that maps $w_{a}$ onto the set $\{\lambda w$ The size of the set of quantities of women John knows in $w$ is 5$\}$. Since this is a singleton set, there is no need to appeal to the pragmatic requirement of maximal informativeness above.

I've demonstrated the meaning of mult questions using a non-dense set (and a count-noun question) so far, as these questions present the clearest illustrations of the second-order measurement process involved in mult questions. I'll briefly extend this discussion to questions involving a dense set of degrees to demonstrate that these work the same way.

When mass nouns are involved in a question, the operator $\mathscr{M}$ is used, rather than the cardinality operator. As in Section $2.3, \mathscr{M}$ is a function from a portion of matter to a dense set of degrees. If a lump of pizza dough weighs 2 pounds, the range of the function is all of the real numbers between 0 and 2. $\mu$ measures the size of a closed interval [b,a] by subtracting its upper bound from its lower bound. This is called the Lebesgue Measure, and is the standard way of measuring subsets of Euclidean space in Measure Theory. $\mu$ is not a maximality operator; whether $D$ is the set of reals from $0-2$, or those from $100-102, \mu(D)=2$. In the case of 
weight, volume, etc., the lower bound will always be zero. So, as in the case of plural count nouns, the measure of the set of measures will always be the same as the maximum measure in the set. ${ }^{7}$

How does a question about the size of the set of quantities of women result in information about the quantities of women, which is what mult questions seem to inquire after? Given that the predicate in (24) and (25) is downward-scalar, the size of the set of amounts of women-he-knows will always be the same as the maximum amount of women-he-knows. This means that there is a one-to-one correspondence between the maximal cît de mult answers ("The size of the set of amounts of Xs...") and $c \hat{t}$ answers ("The amount of Xs..."). ${ }^{8}$ In downward-scalar questions, the hearer can always infer from one to the other.

Upward-scalar questions differ from downward-scalar questions because the inference from the inclusion of a set in the denotation of a VP to the inclusion of its subset does not hold. One can, however, infer upwards from the inclusion of a set of an inclusion of its superset. This means that the sets of degrees denoted by all upward-scalar predicates are infinitely large, which in turn means that the size of the set of quantities of every upward-scalar predicate is always the same. This means that it's impossible to infer from a cit de mult question the maximal answer of its corresponding cît question, and explains the infelicity of (21).

The semantics contributed by mult indirectly results in what appears to be a maximality effect; the addition of mult to a quantity question makes that question compatible with questions asking for a maximum answer, but not with questions asking for a minimum answer. This difference is accounted for without appealing to a maximality operator like the one proposed by Rullman (1995). ${ }^{9}$

\subsection{Non-scalar Questions}

This subsection explores possible ways of extending the above analysis to nonscalar questions. While downward-scalar questions allow inferences from a set to its subset and upward-scalar questions allow inferences from a set to its superset, non-scalar questions disallow inferences to subsets or supersets. An example of the set of degrees denoted by the non-scalar predicate in the question 'How many players can form a basketball team?' is in (26):

$$
\begin{array}{ll}
\text { a. } & \lambda d \exists X \text {. players }(X) \wedge \text { can-form-a-team }(X) \wedge|X|=d \\
\text { b. } & \{4,5,7\}
\end{array}
$$

I argued earlier that $m$-words only modify quantity and gradability scales. This would suggest the possibility that $m$-words are incompatible with non-scalar sets of

\footnotetext{
${ }^{7}$ Thanks to Sam Cumming and Frank Arntzenius for their help here.

${ }^{8}$ Some of my Romanian informants loosely translate mult questions as asking for the 'exact' quantity or the 'exact' answer to the question, an intuition which is captured by the fact that mult questions, unlike monomorphemic questions, always denote a singleton set of propositions.

${ }^{9}$ See also (Comorovski 1996: 39) for a discussion of maximality in English questions arising from the lexical contribution of which, an assumption that explains the awkwardness of the question '\#Which ones, for instance, came to the party last night?'.
} 
degrees like the one in (26b). If this were the case, then cît de mult questions but not $c \hat{t}$ questions would be incompatible with non-scalar predicates. This is true for some speakers:

A basketball team can consist of 4,5 or 7 players.

a. Ion ştie cîţi jucători pot formă o echipă de baschet. John knows cît-Mpl players can form a team of basketball

b. \#Ion ştie cît de multi jucători pot formă o echipă de baschet. John knows cît of many-Mpl players can form a team of basketball 'John knows how many players can form a basketball team.'

However, most of my informants accept (27b), which poses a problem the above account in which $m$-words range only over scales.

Given the acceptability of (27b) (and assuming that $m$-words can in fact modify non-scalar sets of degrees), the compositional analysis makes predictions about its interpretation. Specifically, it predicts that mult measures the size of the set of quantities $\{4,5,7\}$. Unlike with upward-scalar questions, the size of the set of degrees here is not entirely uninformative; it will vary with the predicates and the situation (the size of the set in the above scenario is 3 ; in a situation in which only 4 or 5 players can form a team, the size of the set would be 2).

However, unlike with downward-scalar questions, there is no reliable correlation here between the size of the set of quantities and the maximum quantity. This indicates that, for non-scalar predicates, mult questions cannot be used to ask for a maximum answer. But this does not mean that the interpretation of (27b), as predicted by the analysis above, is meaningless. ${ }^{10}$

Imagine a scenario in which Adrian and Bob are organizing a basketball game with friends. They try to plan ahead despite the fact that their friends are very unreliable and so they doesn't know how many people will show up to play basketball. Bob isn't worried because he knows that basketball allows for a variety of different player configurations. Specifically, he knows that a basketball team can consist of 4, 5, or 7 players. Adrian would like to similarly quell his own anxiety. So he can ask an informative question of his friend Bob that requests information about the size of the set of quantities of players-that-can-form-a-team. In this scenario, the size of the set of possible team-sizes is three.

However, this isn't a felicitous response in this scenario to a mult question for speakers who accept (27b). The most natural answer is instead $\mathrm{B}^{\prime}$.

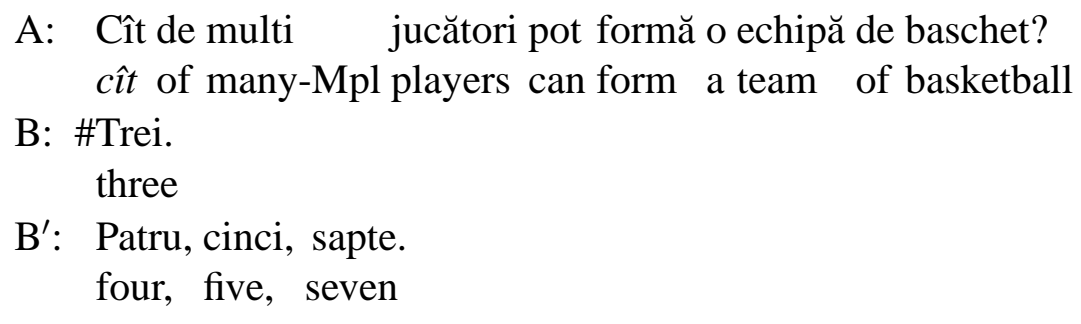

\footnotetext{
${ }^{10}$ Thanks to Sam Cumming and Uli Sauerland for bringing this possibility to my attention.
} 
The same holds in an embedded context: Imagine that Adrian knows how liberal basketball is in the above respect. Namely, he knows that either $x, y$ or $z$ quantities of players can form a team. He does not, however, know the values of $x, y$ and $z$. The embedded question below is judged false in this scenario:

Adrian ştie cît de multi jucători pot formă o echipă de baschet. Adrian knows cît of many-Mpl players can form a team of basketball

To sum up the discussion on non-scalar constructions, it seems reasonable to conclude that $m$-words can't modify non-scalar sets of degrees. If this were the case, mult questions would be incompatible with non-scalar predicates. This seems to be true for some speakers, but not all. If $m$-words are compatible with non-scalar sets of degrees, the analysis above predicts that mult questions would not denote the same set of propositions as their corresponding monomorphemic questions, but rather a singleton set of propositions describing the size of the set of possible quantities of players. This does not seem to be the case. I leave this as an open issue.

\section{Extensions of the Analysis}

This section extends the above analysis by discussing the nature of quantity questions in English and exploring some potentially relevant syntactic properties of monomorphemic and mult quantity questions in Romanian.

\subsection{English Quantity Questions}

It's been clear all along that English quantity questions, which obligatorily have $m$-words, pattern with monomorphemic quantity questions in Romanian rather than with mult questions. If the $m$-words in English quantity questions contributed to the semantics of the question in the same way they do in mult questions in Romanian, English quantity questions would be incompatible with upward-scalar questions.

I propose that the $m$-words in English quantity questions are semantically inert. The $w h$-word for quantity questions ('How many boys...') and the $w h$-word for gradability questions ('How tall...') has the same meaning, just as cît in Romanian has a consistent meaning:

$$
\llbracket \text { how } \rrbracket=\llbracket \text { how } m \text {-word } \rrbracket=\lambda \mathrm{D} \lambda \mathrm{p} \exists \mathrm{d} \cdot \mathrm{p}=\mathrm{D}(\mathrm{d})
$$

The presence of the $m$-word in English quantity questions, given its lack of semantic content, can be explained syntactically. How and [how $m$-word] vary only in their selectional requirements. Alternatively, the presence of the $m$-words in quantity questions could possibly be another instance of ' $m u c h$-support,' introduced by Corver (1997) to explain, among other things, the difference between these data:

a. Robin is too (*much) qualified.

b. John is qualified for the job, but Robin is too *(much) so. 
a. *Sam isn't too taller/more tall than Jessica.

b. Sam isn't too much taller than Jessica.

(31) shows that $m u c h$-support is required when a degree operator modifies the proadjective so but disallowed when a degree operator modifies a lexical adjective. (32) shows that much-support is required when two degree operators (here, too and -er) stack on top of each other.

Such an explanation is particularly attractive because it also explains the corresponding lack of much-support in Romanian.

\subsection{Other Characteristics of Quantity Questions}

This section briefly reviews two characteristics of mult quantity questions in Romanian that shed light on the syntactic differences between them and monomorphemic quantity questions. In monomorphemic questions, the complement of $c \hat{t} t$ seems to be a [+animate] argument. In mult questions, the complement of $c \hat{\imath} t$ seems to be a [-animate] adjunct.

Although these generalizations don't directly bear on the semantic analysis above, they provide support for some background assumptions: a syntax in which the complement of cît is an NP in monomorphemic questions and [mult [ NP ]] in mult questions, and the characterization of mult as a degree modifier.

In Romanian, the accusative marker $p e$ can only occur with animate complements. Keeping quantification over animate entities a constant, $p e$ is grammatical with monomorphemic but not mult questions.
a. Pe cîte femei le cunoaşte? pe cît-Fpl women CL know-3sg?
b. *Pe cît de multe femei le cunoaşte? pe cît of many women CL know-3sg? 'How many (of the) women does he know?'

There are two ways of accounting for the data in (33): first is to argue as I do above that cit consistently quantifies over degrees in both constructions, in which case the distribution of $p e$ above can only be explained syntactically. Such a syntactic explanation could plausibly involve [+animate] $\phi$-features on the $\mathrm{N}^{o}$, independently needed for syntactic accounts of agreement, percolating up to $p e$ in its functional projection in (33a) but blocked in (33b). Second, one could offer a semantic account of the difference above: cît always quantifies over degrees, but it somehow can differentiate between the types of degrees they are: in monomorphemic questions, the degrees represent the size of sets of animate individuals. In mult questions, the degrees represent the size of the set of (inanimate) quantities.

As I do not know how to articulately formalize the latter approach, I'll tentatively espouse the former. Interestingly, we are faced with the same set of options when accounting for scope reconstruction phenomena in these questions.

In cît constructions, the individual quantifier can take wide or narrow scope 
with respect to a modal operator; in cît de mult constructions, the individual quantifier can only take narrow scope.
a. Cîte femei vrea să angajeze? cît-Fpl women want-3sg she hire-3sg
b. Cît de multe femei vrea să angajeze? unambiguous cit of many-Fpl women want-3sg she hire-3sg 'How many women does she want to hire?'
ambiguous

This difference in scope is detectable in Condition C effects in Macedonian. Huang (1993) and Heycock (1995) account for these effects - and those in English below in (36) - by assuming that semantic reconstruction and Condition $\mathrm{C}$ both apply at LF.
a. Kolku knigi za $\operatorname{Dzon}_{i}$ toj $_{i}$ ima pročitano? how books about John he has read how many books about John he has read 'How many books about John did he read?'
b. *Kolku mnogu knigi za Dzon $_{i}$ toj $_{i}$ ima pročitano?

There are two prominent accounts of scope reconstruction in quantity questions (though see Cresti 1998 and Rullman 1995 for alternative explanations). Huang (1993) argues that argument (or predicate) complements of the wh-word allow for the wide-scope reading of the individual quantifier, but not adjunct (or nonpredicate) complements.

(36) a. How many pictures of $\mathrm{John}_{i}$ do you think that he $\mathrm{e}_{i}$ will like?

b. *How proud of $\mathrm{John}_{i}$ do you think he $i$ should be?

In the context of the above approach, Huang's generalization covers the data in (34) nicely: the complement of cit in (34a) is an NP, while the complement of cit in (34b) is a modifier (perhaps in a QP, see Doetjes 1997).

The argument made by Heycock (1995) against Huang's generalization of the data in (36) is based on its incompatibility with the subject-internal trace hypothesis. Heycock proposes instead that the difference between (36a) and (36b) reflects a difference between referential and non-referential phrases. She explains further: " 'nonreferential' is not really an appropriate term: the crucial point here is that the quantification is over amounts, rather than other types of entities" (fn.16).

However, as I mentioned above, this distinction doesn't predict a difference between monomorphemic and mult questions in Romanian, since each type involves quantification over degrees, indicating that an alternative explanation is in order. 


\section{Conclusion}

I have argued with e.g. Hackl (2000) that the semantics of quantity questions and Minimal Number Predicates require the interpretation of a determiner that includes in its definition a measure function. I depart from him in arguing that this meaning should be attributed to covert Quantity Operators, rather than the word many. Evidence for this came from split-NP quantity questions in French and the presence of languages for which quantity questions could or could not have an $m$-word.

I have instead argued that $m$-words are degree modifiers, functions from sets of degrees to a singleton set of degrees $d^{\prime}$ which is the measure of that set. This meaning has previously been used to account for the use of mисh in differential comparatives. I demonstrate that extending this meaning to the word mult in Romanian quantity questions properly accounts for the fact that mult questions, but not monomorphemic questions, are incompatible with upward-scalar predicates. However it remains unclear how to extend the account of downward- and upward-scalar questions to non-scalar questions.

I argue that quantity questions in English involve a semantically inert $m$ word (as opposed to Romanian mult questions). It seems plausible that this difference is related to the fact that English, but not Romanian, has 'much-support' in constructions with other degree operators. Finally, I've demonstrated that additional properties of mult questions indicate that the syntactic nature of the complement of cit in these constructions makes a difference for the scope possibilities of the individual quantifier.

\section{References}

Abeillè, A., O. Bonami, D. Godard, and J. Tseng: to appear, 'The Syntax and Semantics of French de- $N^{\prime}$, Travaux de Linguistique.

Abney, Steven: 1987, The English Noun Phrase in its Sentential Aspect. Doctoral Dissertation, MIT, Cambridge, Ma.

Beck, Sigrid and Hotze Rullman: 1999, 'A Flexible Approach to Exhaustivity in Questions', Natural Language Semantics 7, 249-298.

Bresnan, Joan: 1973, 'Syntax of Comparative Clause Construction in English', Linguistic Inquiry 4, 275-344.

Comorovski, Ileana: 1996, Interrogative Phrases and the Syntax-Semantics Interface. Kluwer, Dordrecht.

Corver, Norbert: 1997, 'Much-support as a Last Resort', Linguistic Inquiry 28, 119-164.

Cresswell, Max: 1976, 'The Semantics of Degree', in B. Partee (ed.), Montague Grammar. Academic Press.

Cresti, Diana: 1998, 'Extraction and Reconstruction', Natural Language Semantics 3, 79-122.

Dayal, Veneeta: 1996, Locality in WH-Quantification. Kluwer, Dordrecht. 
Dobrovie-Sorin, Carmen: 1992, The Syntax of Romanian, Comparative Studies in Romance. Foris, Dordrecht.

Doetjes, Jenny: 1997, Quantifiers and Selection. Doctoral Dissertation, Leiden University.

Fox, Danny: 2000, Economy and Semantic Interpretation. MIT Press, Cambridge, MA.

Hackl, Martin: 2000, Comparative Determiners. Doctoral Dissertation, MIT, Cambridge, MA.

Heycock, Caroline: 1995, 'Asymmetries in Reconstruction', Linguistic Inquiry 26, 547-570.

Huang, James C-T.: 1993, 'Reconstruction and the Structure of VP: some theoretical consequences', Linguistic Inquiry 24, 103-138.

Karttunen, Lauri: 1977, 'Syntax and Semantics of Questions', Linguistics and Philosophy 1, 3-44.

Kayne, Richard: 2005, Movement and Silence, Chapt. A Note on the Syntax of Quantity in English, 176-214. Oxford University Press.

Keenan, Edward: 1996, 'The Semantics of Determiners', in S. Lappin (ed.), The Handbook of Contemporary Semantic Theory, 41-63. Blackwell.

Kennedy, Chris: 1999, Projecting the Adjective: The syntax and semantics of gradability and comparison. Garland Press.

Klein, Ewan: 1982, 'The Interpretation of Adjectival Comparatives', The Journal of Linguistics 18, 113-136.

Lahiri, Uptal: 2002, 'On the Proper Treatment of "Expletive $w h$ " in Hindi', Lingua 112, 501-540.

McConnell-Ginet, Sally: 1973, Comparative Constructions in English: A Syntactic and Semantic Analysis, Doctoral dissertation, University of Rochester.

Obenauer, Hans-Georg: 1984, 'On the Identification of Empty Categories', The Linguistic Review 4, 153-202.

Partee, Barbara: 1989, 'Many Quantifiers', in d. Powers (ed.), ESCOL 89: Proceedings of the Eastern State Conference on Linguistics, 383-402.

Rett, Jessica: 2007, 'Evaluativity as Degree Modification'. Ms., Rutgers University.

Rizzi, Luigi: 1990, Relativized Minimality. MIT Press, Cambridge, MA.

Romero, Maribel: 1998, Focus and Reconstruction Effects in Wh-Phrases. Doctoral Dissertation, University of Massachusetts, Amherst.

Rullman, Hotze: 1995, Maximality in the Semantics of Wh-Constructions. Doctoral Dissertation, University of Massachusetts, Amherst.

Schwarzschild, Roger: 2006, 'The Role of Dimensions in the Syntax of Noun Phrases', Syntax 9, 67-110.

Westerstähl, Dag: 1985, 'Logical Constants in Quantifier Languages', Linguistics and Philosophy 8, 387-415.

Wheeler, Samuel: 1972, 'Attributives and their Modifiers', Noûs 6, 310-334.

Zwart, Jan-Wouter: 1997, The Morpho-Syntax of Verb Movement: A Minimalist Approach to Dutch Syntax. Kluwer, Dordrecht. 